\title{
Growing up in the Third Wave: democratic transitions and support for redistribution
}

\author{
Edward Ngai* \\ Date: March 25, 2022 (MPSA version $)^{\dagger}$
}

\begin{abstract}
Variation in experiences of democratic transition have durable effects on political attitudes. I find that the experience of "distributive" transitions to democracy centered on economic inequality between the ages of 18 and 25 has a durable positive effect on support for redistribution by tying redistribution to the idea of democracy. Using data from the World Values Survey (WVS) in 36 countries that transitioned during the Third Wave (1980-2000), I show that these effects cannot be attributable to period effects, birth cohort effects, or any country-specific time-invariant characteristics. They are also robust to the inclusion of past experiences of the economy and welfare state, individual controls, and a range of alternative specifications. I find that distributive transitions affect future attitudes by associating democratic redistribution with government protection, increasing the magnitude and scope of mass attitudinal change for those socialized in scarce economic conditions. Even in weak institutional contexts like post-Third Wave regimes, I argue collective transition experiences durably affect future attitudes through country- and age cohort-specific cultures of conditional social solidarity.
\end{abstract}

Keywords: democratic transitions, redistribution, backsliding, political culture

*Ph.D. Candidate, Department of Government, Harvard University. ngai@g.harvard.edu.

${ }^{\dagger}$ Supplemental appendix available here. This draft is constantly under revision. For the latest version of the paper, click here. Many thanks to Fernando Bizzarro, Fran Hagopian, Peter Hall, Hanno Hilbig, Steve Levitsky, Ruofan Ma, and Yuhua Wang for their patient advice and encouragement. 


\section{Introduction}

Are people who experience democratic transitions centered on ideas of economic social justice more supportive of redistribution? Conversely, do transitions fought around other, non-distributive ideas of democracy, like elections or political rights, lead to more liberal attitudes? Evidence from 75,000 respondents in 36 Third Wave countries shows that growing up in "distributive" transitions "fought around distinct and identifiable inequalities" have durable effects on political attitudes. By matching self-reported individual beliefs with variation in transition experiences, macroeconomic conditions, and measures of age, period, and cohort effects at various points in the life span, I find that collective experiences of democratic transition produce cohort effects of their own. Standard explanations of redistributive attitudes like country-level inequality and material prosperity during the respondent's "impressionable" years insufficiently explain these effects. I argue that distributive transitions affect future attitudes by associating democratic redistribution with government protection. As such, the effect of transition experiences on attitudes should be even more pronounced for cohorts socialized in scarce economic conditions.

Perhaps the ideal-type "distributive" Third Wave transition (and so coded by Haggard and Kaufman owing to the causal importance of both mass protest and economic demands in motivating them) is the one that occurred in Argentina. The winner of the first democratic elections after a repressive military dictatorship, Raul Alfonsin made such a distributive idea of democracy a centerpiece of his campaign and presidency, at least discursively. "With democracy, you can not only vote, but eat, educate, and heal," he famously declared in his first speech as president-elect. Contrast this with the view of Corazon Aquino, figurehead of a "liberal" transition and winner of the Philippines' first democratic elections after the Marcos dictatorship: "It's true you cannot eat freedom and power machinery with democracy. But neither can political prisoners turn on the lights in the cells of a dictatorship." Of course, reasonable people will disagree on whether particular transitions are "distributive" or "liberal." Even so, different coders have high levels of agreement with each other about the causal factors leading to transition (see appendix S3).

Distinguishing between the way political leaders frame the idea of democracy during democratic transitions and accounting for the distributive policies implied by the idea of democracy adds to the rich scholarship in "transitology" arguing that the way regimes are born durably influences their present and future character (e.g. O’Donnell 1988, Hagopian 1990). This scholarship has been criticized both empirically as well as theoretically (e.g. Geddes 1999, Levitsky and Murillo 2009). If many Third Wave institutions are actually just institutions "on paper," prone to weakness and low levels of enforcement, transition-period effects cannot reproduce themselves through standard models of path-dependence relying on "critical" junctures of institutional change (e.g. Esping-Anderson 1990, Collier and Collier 1991). Accepting these critiques, I argue that collective experiences affect political attitudes durably into the future through cultural path dependence. The idea is that institutional change- from regular public policymaking to social revolution-carries with it changes in values and strategies of action incentivizing 
certain ways of thinking over others. In spite of the institutional weakness that characterized them, Third Wave transitions have had durable effects on the way people think about democratic redistribution.

The paper proceeds as follows. Section 2 reviews the literature on the cohort effects associated with past collective experiences. Sections 3 and 4 describe the data and empirical strategy. Section 5 presents the results. Section 6 discusses the ways transition experiences might affect democratic cultures of social solidarity and implications for regimes. Section 7 concludes and section 8 documents various robustness checks.

\section{How past experiences affect future attitudes}

Where do political preferences come from? A large and diverse literature has honed in on the critical role of past experiences in the formation of current attitudes. I focus on studies producing quantitative estimates using observational causal inference, but this is well-trod ground for cultural sociologists who focus on the everyday narratives and rituals that make up the "scripts" of personhood. For example, Pharr (1981) attributes the career choices of modern Japanese women to the ideas of womanhood made accessible to them by their mothers. ${ }^{1}$ These ideas transformed daughters into "political women" who, in turn, became agents of social change.

The seminal quantitative cross-national account of attitude formation is the work associated with Ronald Inglehart and colleagues. For example, young people are more likely to be happy (Inglehart 2002), support gender equality (Inglehart and Norris 2003), and vote for mainstream parties (Norris and Inglehart 2019). He explains this relationship by arguing that people's values reflect the levels of economic scarcity they experience as they enter adulthood. As such, it explains generational differences in attitudes by appealing to universal processes of social modernization driven by the positive long-term trend of economic growth (1990, p. 68). In age-period-cohort terms, this is saying the observed effect of age on attitudes is made up entirely of the cohort effects associated with material prosperity. ${ }^{2},{ }^{3}$ It is a productive simplification given the identification issues associated with separating period from cohort, but not fully credible when applied to situations where period effects are well-documented, such as in

${ }^{1}$ Of the thirteen women in Pharr's interviews whose parents had opposing attitudes about gender roles, the daughter sided with the mother all thirteen times (1981, p. 96).

${ }^{2}$ Inglehart and Welzel (2005, p. 38) seem aware of this when they concede that the security afforded by material prosperity "can be eroded by short-term period effects and... catastrophic events," repeatedly reminding readers that value change is reversible. But then they wave the entire issue away (after carving out an exception for the fall of communism) saying "such catastrophic events are rare" (and perhaps they were in the study period, 1985-2005). I also object to how the post-industrial economy is described. New research probing the desperate underbelly of the tech economy, like the lives of remote tech contractors (e.g. Gray and Suri 2019) shows that knowledge economies do not universally provide "much higher levels of existential security and individual freedom" (pp. 37-8).

${ }^{3}$ Assuming away period effects equates the effect of living in a rich country in 1945 on attitudes in 1965 to living in a rich country in 2000 on attitudes in 2020, despite the fact that a life of postwar luxury- big yard, big car, big family-is decidedly not the paragon of modern prosperity. 
development strategies. ${ }^{4}$ When estimates of cohort effects are confounded by period effects, misleading estimates of the relationship between age and attitudes can result. ${ }^{5}$

Cross-unit approaches have produced increasingly precise deductions about the "exogenous" shocks that accompany attitudinal change. For example, Guiliano and Spilimbergo (2014) find that recessions increase support for redistribution through universal microfoundations like changing belief systems and trust in government. However, other authors have drawn attention to how the effects of collective experiences are actually conditioned on economic context. For example, Neundorf and Soroka (2018) show that the way British adults respond to recessions is conditioned on the generosity of the welfare state they experienced as youth. Here, macro-shocks interact with the welfare institutions respondents experience growing up.

Following this insight, I argue that variation in transition experiences affects future attitudes by changing the way people think of democratic redistribution. Those who grow up in distributive transitions centered on visions of economic justice are more likely to consider government redistribution to be a normative right, especially in bad times. Empirically, this should reveal itself in bigger and less discriminate effects of transition type on attitudes for those who also grew up in bad economic times. Those who grow up in liberal transitions react the opposite way: they are unlikely ever to believe that the government take more responsibility for the poor, not least when they are confronted with bad economic conditions. Instead, they argue that the poor should take more responsibility to provide for themselves instead. Neundorf and Soroka (2018) call these dueling patterns of redistributive policy preferences the "government redistribution hypothesis" and the "luxury good hypothesis." I show the effect of growing up in recessions on which effect prevails is contingent on experiences of democratic transition.

\section{Empirical strategy and model}

The goal of this paper is to identify how experiencing macro-political change influences beliefs later in life. Here, I use variation in the policy paradigms associated with democracy during Third Wave transitions as a measure of past political experiences, but this approach is generalizable to measures of all kinds of macro-social shocks. I argue that this variation has durable effects on future attitudes by introducing mass publics to "just world" narratives which vary in their distributive implications. These democratic narratives and the policy paradigms they are associated with are more likely to be adopted

\footnotetext{
${ }^{4}$ As Gerschenkron (1962) observes, some countries inherited contexts suitable for "factories quick!" and others did not.

${ }^{5}$ For example, Down and Wilson (2013) find that the effect of age alone on support for the EU is positive- young people seem less supportive of the EU. But after properly accounting for period effects associated with levels of European integration (or national state evisceration) over time, the coefficient reverses and young people are revealed to be more supportive. Inglehart and Welzel (2005, p. 38) claim that "a society's prevailing sense of existential security is more important than cognitive [and experiential] factors." But this is largely unprovable without testing the effect of growing up in material prosperity against other society-specific macro-experience that might affect attitudes. For more discussion of the challenges of separating period from cohort, see appendix S4.
} 
by those who were in their "impressionable" ages when they encountered them.

Because cohorts share so many experiences in common, ranging from economic and political shocks to global trends in technology or culture, identifying "macro-shock effects" is impossible using only over-time variation. But because Third Wave transitions occurred across such a wide range of country contexts, it is possible to use cross-national and cross-cohort variation in experiences of past events to identify how transitions affect attitudes. I estimate the effect of country- and cohort-specific transition "shocks" by leveraging this variation. The main independent variable, experiencing different kinds of democratic transitions between the ages of 18 and 25, is the interaction between transition cohort and transition type.

In the World Values Survey (WVS), each respondent is nested in three periods and cohorts each with distinct causal effects. For example, for a 45 year-old Mexican surveyed in 2020, I consider the Mexican transition (liberal), the year it occurred (2000), the respondent's age at the time (25), the time elapsed between treatment and observation (20 years), and measures of the Mexican economy during the respondent's impressionable years (1992-2000). Assuming the respondent's year of birth is conditionally random, the effect of growing up in a transition on attitudes can be identified as follows. First, by using survey year fixed effects, I control for secular global trends in beliefs about democracy. Then, to ensure that the resulting country-level variation in beliefs is not being driven by effects associated with period or (birth) cohort effects that have nothing to do with experiences of democratic transition, I include dummies for birth cohort and the time between the transition (treatment) and survey (observation).

$$
\begin{array}{r}
Y_{i t c}=\boldsymbol{\beta}_{\mathbf{1}}\left(\text { dist }_{c} \times \operatorname{trans}_{i} \times \operatorname{recession}_{i c}\right)+\boldsymbol{\beta}_{\mathbf{2}}\left(\text { dist }_{c} \times \operatorname{trans}_{i} \times \text { gini }_{i c}\right) \\
+\beta_{3}\left(\text { dist }_{c} \times \text { trans }_{i} \times \text { welfare }_{i c}\right) \\
+X_{i}+\delta_{c}+\gamma_{t}+\eta_{q}+\epsilon_{i t c}
\end{array}
$$

where $Y_{i t c}$ is individual $i$ 's beliefs in country $c$ in year $t, \boldsymbol{\beta}_{\mathbf{1}}$ is a vector corresponding to each of seven coefficients in the three-way interaction (three predictors, three two-way interactions, and the three-way interaction itself), $\boldsymbol{\beta}_{\mathbf{2}, \mathbf{3}}$ are vectors corresponding to sets of four coefficients for each additional economic indicator (the indicator, two two-way interactions, and a three-way interaction), dist $t_{c}$ is a binary variable coded 1 if Haggard and Kaufman (2012) code the transition as "distributive," trans $s_{i}$ is the transition cohort coded 1 if individual $i$ was between the ages of 18-25 during the transition year, recession $i c$, gini $_{i c}$, and welfare ic $_{i c}$ are the 7-year rolling averages of several macroeconomic indicators in country $c$ when individual $i$ was in their impressionable years $19-25,{ }^{6} X_{i}$ are the individual controls, $\gamma_{t}$ are survey period fixed effects, $\eta_{q}$ are birth cohort fixed effects, and $\delta_{c}$ are country fixed effects.

\footnotetext{
${ }^{6}$ Findings are robust to ages 19-23, 18-24, and 17-25, see appendix S6.1
} 


\section{Data}

What counts as a democratic transition and when precisely they occur is a long-running debate in our discipline. For simplicity and coverage, I follow the Polity 5 codings of regimes and transitions. Data for individual attitudes about redistribution are from all the World Values Survey for which the questions were asked (1995-2020). Missing variables, mostly caused by sparse unemployment and inequality statistics, are deleted listwise. The result is a time-series cross-section of about 75,000 respondents in 35 countries and 66 country-survey-years, all of whom were either born shortly after a democratic transition or experienced it firsthand. Importantly, each respondent is fully nested into several mutually exclusive units: country; birth, transition, and survey year periods; and birth and transition cohorts. I leverage this data structure to address potential omitted variables by incorporating a wide range of fixed effects and control for observable characteristics and past exposure to macroeconomic shocks. A full list of the Third Wave countries, transitions, and survey years in the data are available in appendix S2.

\section{Dependent variables}

Support for redistribution: survey items from the World Values Survey (WVS) are commonly used in individual-level research on political attitudes. They are measured through a battery of questions asking about agreement with various statements on a 10-point scale. My main dependent variable is a question where 1 represents full agreement with "Incomes should be more equal" and 10 with "We need larger income differences as incentives for individual effort." A second dependent variable focuses on social solidarity with the poor. This question asks whether "the government should take more responsibility to ensure everyone is provided for" or "people should take more responsibility to provide for themselves." Full reproductions of all the survey questions used in the study are in appendix section S2. For ease of interpretation, all scales are transformed so higher values represent more support for redistribution.

\section{Independent variables}

Transition type: the primary source of variation in past experiences is in the ideas of democracy each respondent experiences during democratic transition. There are many paths to democracy, each with their own distinctive coalitions, rituals, and conceptions of "the people" (e.g. Collier 1999). Haggard and Kaufman (2012, p. 500) code all transitions that occurred between 1980 and 2000 as "distributive" if regime debates are "fought around distinctive and identifiable inequalities," and "non-distributive" if threats "that risk the redistribution of assets and income... did not occur at all or appeared to play only a marginal causal role." Throughout, I use "liberal transition" as a replacement for "non-distributive" transition. Their codings produce 43 Third Wave transitions in 40 countries with distinct variation in ideas and processes of democracy animating transition narratives and processes: 25 "bottom-up" distributive transitions, and 18 "top-down" liberal transitions. ${ }^{7}$ Unfortunately, about a third of these countries will be

\footnotetext{
${ }^{7}$ Haggard and Kaufman (2012) adopt an intentionally generous definition of what counts as a "distributive" transition.
} 
dropped owing to a paucity of economic data. A full list of the remaining countries and their Haggard and Kaufman codes are available in appendix section S2. For more discussion of the Haggard and Kaufman codes, whether they capture the universe of variation in causal processes or ideas, and comparison of their codes with other measures of transition type, see appendix S3.

Age: age effects are attitudinal changes that occur as people get older. Increasing age has welldocumented effects on political attitudes, including increased support for redistribution (Alesina and Guiliano 2011) and for radical right voting (Norris and Inglehart 2019). Importantly, any model including age implicitly includes period and cohort effects, since each of age, period, and cohort are completely determined by the other two. But failing to account for all three effects means it is impossible to know whether an individual's reported attitudes are attributable to their age, secular time-varying conditions that have nothing to do with their age, or membership in a specific cohort.

Other individual controls: Whereas the experience of a collective event- barring maybe a calendar change- cannot affect one's age, variation in macro-contextual features like political system or "good" or "bad" times economically have well-documented effects not only on on individual-level characteristics that can shape preferences into the future (e.g. Alesina and Guiliano 2011, Alesina and Glaeser 2004). Growing up in certain environments can affect beliefs through individuals' willingness to do things like work hard or invest in education. I include the following individual-level characteristics as controls: gender, income, education, employment status.

Economic socialization: I compute country-birth cohort level means for economic indicators in respondents' impressionable years and code the top quartile as "rich country" (development), "recession" (economic growth), "unequal country" (income inequality), and "welfare state" (level of redistribution). GDP data are from the World Bank and inequality data are from Solt (2020). Cross-country and crosscohort variation on these indicators is necessary for identification of transition cohort effects. Different age cohorts across Third Wave countries experienced considerable variation in economic conditions. Figure 1 reports socializing experiences of economic growth (figures for other indicators are in appendix S1). To illustrate, in Eastern Europe and some parts of Latin America, the cohorts born between 1965 and 1975 (4th-6th) experienced serious economic recessions as youth. However, in Korea, Thailand, and Chile, the same cohort grew up having experienced years of sustained economic growth. Following Guiliano and Spilimbergo (2014), I convert each economic socialization variable to a binary measure based on the top quartile of all country-cohorts in the Third Wave. The cut-offs are as follows:

Rich country: country-year income per capita > \$7856 PPP-adjusted 2015 US dollars

Recession: country-year GDP growth $<2 \%$

Unequal country: country-year disposable income Gini $>0.46$

Welfare state: country-year difference between market and disposable income Gini $>0.1$

Period fixed effects: period effects are responses to secular trends in society or specific events that

Of course, the existence of redistributive demands during the transition period hardly translates automatically to an idea of democracy that necessitates redistribution. Regardless, whatever variation is captured in their codings is my main independent variable. 
affect everyone, regardless of age. For example, surveys conducted in countries that transitioned to democracy at the height of U.S. unipolarity might be associated with more pro-U.S. attitudes. Or, people who experience macroeconomic uncertainty, regardless of its cause or at what age it occurs, might be more supportive of redistribution. Finally, attitudes may change or fade purely due to the passage of time. These period effects are represented in the model by survey and transition year fixed effects.

Birth cohort fixed effects: birth cohort effects are responses to social and historical changes affecting specific groups with shared experiences attributable to the time of their birth. It describes aggregate changes in societal attitudes owing to generational replacement. Inglehart $(1971,1990)$ argues that the experience of material prosperity in one's youth has durable effects on one's value orientation later in life. These effects are modeled straightforwardly using seven-year averages of modernization-related macroeconomic variables constructed for the years where each respondent was or would be between the ages 19 and $25 .^{8}$ All further variation owing to birth cohort is controlled for using birth cohort fixed effects. Following Alwin and Krosnick (1989), common experiences at a certain moment in time do not affect all age groups equally. Specifically, "impressionable" cohorts which experienced transition between ages 18 and 25 are more likely to develop durable attitudes in response to transition experiences.

\section{[FIG 1 ABOUT HERE]}

\section{Results}

\section{[TABLE 1 ABOUT HERE]}

Table 1 presents the results of several model specifications. A positive coefficient means more agreement with the statement "incomes should be more equal" (and disagreement with the statement "income differences should be greater as incentive for hard work"). ${ }^{9}$

Models 1 and 2 are tests of the Inglehart model. They are evidence that collective experiences like democratic transitions do not affect attitudes through a fixed set of qualities, but through the way these experiences are contextualized through the beliefs associated with economic conditions at a certain age. In model 1, neither transition experiences nor growing up in a rich country affect support for redistribution. However, when these variables are interacted in model 2, the effect of transition experiences on attitudes is conditional on economic scarcity at an impressionable age. In rich countries, young people who grew up in distributive transitions treat redistribution as government protection, whereas those who grew up in liberal transitions treat it as a luxury good. These results show that both economic context

\footnotetext{
${ }^{8}$ Krosnick and Alwin (1989) identify the 18-25 age range as the "impressionable" ages after which attitudes remain stable over the rest of the life span. For ease in constructing rolling averages, I remove age 18 (though the finding is robust to other changes in this measure, see part 7).

${ }^{9}$ Similar results are obtained using agreement with the statement "government should take more responsibility to ensure everyone is provided for" and disagreement with "people should take more responsibility to provide for themselves." These results are discussed in part 7.
} 
and transition experiences have socializing effects on political attitudes, including about redistribution. Importantly, these effects are conditioned on both transition type and economic socialization: different transition experiences have opposing effects on those growing up in scarce economic conditions.

Models 3, 4, and 5 extend the interactive model with finer-grained measures of economic context: recession, income inequality, and welfare spending. ${ }^{10}$ Most importantly, the coefficient on the variable indicating that the respondent experienced a distributive transition between ages 18-25 is positive, increasing in significance with each specification. This indicates that the cohort effects associated with democratic transitions themselves affect attitudes, independent of economic conditions in respondents' impressionable years. Growing up in a Third Wave distributive transition is associated with about a 0.25-point increase in agreement that incomes should be more equal, comparable to the effect of falling two deciles in the income scale.

The interactive terms are informative about the mediating effect of economic socialization on transition experiences. For those who grew up in a recession (model 3), liberal and distributive transitions have diametrically opposed effects on future attitudes regardless of the age respondents experienced them. Conditioning on recession socialization, those who experience distributive transitions are a full point more supportive of income equality- the effect of falling nine income deciles. Recession socialization has an interactive effect with the effect of distributive transitions, both in magnitude (double) and in reach (across cohort). The effect is robust to the inclusion of income inequality (model 4) and the welfare state (model 5) during respondents' impressionable years. Results for individual controls are shown in appendix S5. Consistent with the literature, women and the unemployed are more supportive of redistribution, and higher-income, more-educated respondents are less supportive.

In summary, distributive transitions are associated with more support for redistribution for those who experienced them between the ages of 18-25 and those socialized in recessions. The interactive effects show that experiencing different kinds of democratic transitions have effects that are conditional on economic socialization, the content of transition experiences, and the age at which one encountered them. Importantly, different kinds of transitions have diametrically opposed effects on the way people conceive of democratic redistribution. This implies that transitions have particularly strong and durable attitudinal effects on the impressionable and those socialized in challenging economic conditions. Possible explanations for this conditional relationship are explored in the next section.

\section{Mechanisms: path-dependent cultures of social solidarity}

The previous section has argued that democratic transitions have socializing effects on those who were socialized in recessions and those who were at an impressionable age when they occurred. But many events have intervened between the Third Wave and survey observation, including institutional change. How can collective events long ago affect future attitudes if welfare institutions are undeveloped, unstable, or otherwise unable to shape attitudes and develop coalitions for redistribution; or if personalist

\footnotetext{
${ }^{10}$ Development (income per capita) is replaced in this model owing to collinearity (inadequate cohort-level variation)
} 
parties and inchoate party systems inscrutably structure programmatic competition; or if democratic institutions themselves are inadequately consolidated for popular attitudes to influence distributive policy? Even in the context of weak institutions, collective experiences of democratic transition can still durably affect future attitudes through cultures of social solidarity. Hall (2017) argues that support for redistribution is rooted in political cultures of democratic redistribution. For example, the Swedish have both high levels of support for redistributive policies as well as an expansive, country-specific conception of democratic citizenship: the nation as the "folkhem," or "people's home." ${ }^{11}$ Like those who grew up in interwar Sweden, people who grow up in distributive transitions might have greater access to collective imaginaries with distinctly "redistributive" visions of social justice, legitimating and driving demand for distributive policy. ${ }^{12}$ It follows that people who grow up in distributive transitions have greater access to collective imaginaries with distinctly "redistributive" visions of social justice, increasing demand for new, country-specific ideas of democracy that emphasize taxing the rich and providing for the poor. Differences in attitudes should be especially pronounced amongst those who experienced the transition at the "impressionable" ages of 18 to 25 .

The idea is that institutional change always has cultural content. Ingram and Schneider (1993) develop an influential typology of how institutional change target and socially construct groups and group cultures. Where democratic institutions are associated with economic justice, welfare recipients are more likely to be "positively" socially constructed (i.e. deserving). Where they are associated with the "American dream," welfare takes on a decidedly negative social construction reserved for "deviants" (or worse, "contenders" perfectly able to pull themselves up by the bootstraps but choose to free-ride on government instead). It follows that exposure to different ideas of democracy at key points in the life span would affect one's agreement with the idea that "incomes should be greater to incentivize hard work." These cohorts represent new "political generations" with distinct attitudes about redistribution (e.g. Grasso et al. 2019).

Within the realm of national or age-group cultures, past experiences can affect future attitudes through many pathways consistent with conditional distributive solidarity. Three kinds of "value change" are tested in detail:

1) experiencing distributive transitions decrease peoples' willingness to take risks or believe in a "just world" where people get what they deserve in the future;

2) experiencing distributive transitions increases the association between redistributive policies and democracy itself;

3) the shared experience of struggling for redistributive policies during democratic transitions reinforces material values.

I consider each of these mechanisms through a series of placebo tests. Table 2 presents these re-

11 "The Swedish social democrats reshaped the national collective imaginary in ways that reinforced social solidarity for decades to come," Hall observes (2017, p. 218). "Egalitarian ideals became a part of Swedish identity."

${ }^{12}$ On the flip side, those who grow up in liberal transitions may be more likely to associate democracy with elections, civilian rule, or a range of any other country-specific institutional forms. 
sults. In summary, there is little evidence that variation in transition experiences increases the pessimism of just world beliefs, critical citizenship, or respondent propensity to believe that democracy is about redistribution. However, growing up in distributive transitions is associated with increasing materialism, with consequences for support for democracy in general.

\section{[TABLE 2 ABOUT HERE]}

Models 1 and 2: generalized beliefs about a just world. The previous section has argued that growing up in distributive transitions increases support for redistribution by associating democratic redistribution with government protection. However, collective experiences can affect attitudes about redistribution not through changing beliefs about government policy, but the degree of "optimism" one has about a just world in general (Benabou and Tirole 2006). For example, events that make people believe that "hard work does not lead to success" or that "competition is harmful and brings out the worst in people" might also be associated with increased support for government redistribution. None of the theoretically important coefficients are significant, indicating that the cohort effects associated with distributive transitions cannot be explained by changing just world beliefs.

Models 3 and 4: the idea of democracy as redistribution. Variation in transition experiences may affect future attitudes by changing distributive policies associated with the idea of democracy itself. Knutsen and Wegmann (2016) show that there is a great deal of variation in what people think democracy means across space and time. Distributive transitions centered on visions of economic social justice may socialize people into collective imaginations of democracy that imply more redistribution. Models 3 and 4 substitute survey items asking "how essential" taxing the rich and supporting the poor, and providing government aid for the unemployed are to the idea of democracy. The results are insignificant on the relevant variables, indicating that transition experiences affect cultural attitudes about redistribution, not democracy.

Models 5 and 6: the "silent revolution reverses." Inglehart (1990) argues that as societies develop, "materialist" concerns like economic redistribution should recede in importance and be replaced with "post-material" issues like social, identity group, and environmental rights. This conceives of democratization as a consequence of the socializing effects of economic development. In my account, post-material value change does not follow automatically from economic context, but conditionally based on the way political actors frame distributive policies during democratic transitions. Model 5 uses the main 5-item post-materialism index from Inglehart (1990) and Inglehart and Welzel (2005) as the dependent variable. It shows that distributive transitions are associated with an 0.3-point decrease in post-materialism for those who experienced transitions between ages 18 and 25. In unequal countries, the effect doubles and is unmitigated by inclusion of Third Wave-sized welfare states. Model 6 uses a question asking agreement with the statement that "democracy is the best form of government." Growing up in liberal and distributive transitions have diametrically opposed effects on support for democracy in general. For those who were also socialized in recessions or high levels of income inequality, the interactive effects 
of transition type are even more pronounced.

\section{Framing democracy: the legacy of the Third Wave on redistributive attitudes}

For a generation of political scientists, the Third Wave was euphoric proof that democracy was "the only game in town." But the record of Third Wave democracies is poor. Mainwaring and Bizzarro (2019) find that only a quarter of the 91 new democracies inaugurated since 1974 have consolidated in any meaningful sense. I argue that the failure of democratic consolidation in Third Wave democracies lies partly in the nature of the transitions from which they originated. Specifically, young generations who experience distributive transitions associate democracy with government redistribution in bad times. By rhetorically animating the idea of democracy with material values and redistributive policies, political actors framing distributive transitions depress postmaterial value change with deleterious consequences on overall support for democracy.

This paper makes three interventions into the literature on democracy and redistribution. First, I show that attitudes about redistribution are conditioned on both collective transition experiences and economic conditions in one's impressionable years. Second, I re-emphasize that variation in democratic transitions durably affects the future of democratic regimes, in Third Wave countries through path-dependent cultures of social solidarity. Finally, I argue the rise of authoritarian populism in new democracies has roots in the nature of Third Wave transitions themselves.

Inglehart and Norris (2017) memorably describe the rise of right-wing populism in recent years as "the silent revolution in reverse." They argue that the generations socialized in economic prosperity remain as postmaterial as they always were, but the value-changing period effects associated with decades of low growth and high inequality have increased mass demand for populist, right-wing politics in general. "There was no evidence of life-cycle effects. . . but at any time point, current socioeconomic conditions could make the population as a whole more (or less) Materialist- and more (or less) likely to support xenophobic parties," they write (p. 446, emphasis my own). Assuming the life-cycle effects associated with economic socialization continue trending in the post-materialist direction, this implies there is nothing that can be done about the rise of right-wing populism besides wait for the return of sustained economic growth or, as they euphemistically call it, "generational replacement."

Using the same survey data (admittedly from a different subset of countries), I find that the cohort effects associated with economic socialization on redistribution (and indeed, postmaterialism) are themselves conditioned on experiences of democratic transition. Collective experiences cast previous events in a new light, suggesting different redistributive policies and strategies of individual action depending on the way the idea of democracy is framed. I call this "the silent revolution reverses." In the Third Wave countries, it is the generations who grew up in material prosperity and experienced distributive ideas of democracy at an impressionable age who are more likely to possess materialist values consistent with 
support for right-wing authoritarianism.

If that is a bit depressing, the good news is that transition experiences are just single items on extensive "scripts of personhood" that individuals call on to make sense of their everyday lives, exogenous society-wide shocks, and everything in between. Life in a Third Wave country between the years 1980 and 2000 was special and has left a lasting impression on the young people who were there. But normal political life, no matter which "wave" one's democracy is born in, does not have to be less special. Surely many other collective events have durable cohort effects on future attitudes. By imbuing these events, real or imagined, with cultures of social solidarity, there is much political actors can do to impact the future attitudes of those who grew up in the Third Wave.

\section{Robustness tests}

Alternative measure of support for redistribution. I substitute the WVS question about income equality with one asking for agreement with the idea that "government should take more responsibility to ensure everyone is provided for" (vs. "people should take more responsibility for themselves"), with no substantive differences to the magnitude and significance of the theoretically important coefficients. Results are presented in appendix S7.1.

Alternative specifications of independent variables. The analyses are re-run with different codings for variation in transition type (from Treisman 2020), macroeconomic socialization periods (5- and 9year rolling averages), birth cohorts (5- and 10-year), and periods since transition (5- and 10-year) with no substantive difference in results.

Alternative estimator. The standard two-way fixed-effects estimator has well-documented biases under staggered treatment timing (Callaway and Sant'Anna 2021, Goodman-Bacon 2021). The two-way fixed effects estimator proposed by Sun and Abraham (2021) allows for staggered rollout by conceiving of macro-shocks as cohort-specific treatments in relative time. This approach is almost theoretically similar to my conceptualization of transitions as country-specific shocks of ideas preceding (survey) observation by various time periods.

Reverse causality. The previous sections have argued that growing up in distributive transitions increases support for redistribution by associating the idea of democratic redistribution with government protection. Without pre-transition survey data for the countries coded by Haggard and Kaufman (2012), it is not possible to completely rule out the possibility that pre-transition attitudes cause variation in transition ideas or processes. Such an account would argue that the attitudes and strategies of action of cohorts younger than the "impressionable" 18-25 age cause both variation in transitions and cohort-level support for redistribution. Appendix S7.2 presents the results of the model for those aged 0-18 when they experienced democratic transition. None of the theoretically relevant coefficients are significant, indicating that the attitudes of children were unlikely to have caused variation in transition type during respondents' impressionable years. 


\section{References}

Alesina, A., \& Glaeser, E.(2004). Fighting poverty in the US and Europe: A world of difference. Oxford University Press.

Alesina, A., \& Giuliano, P. (2011). Preferences for redistribution. In Handbook of social economics (Vol. 1, pp. 93-131). North-Holland.

Alesina, A., \& La Ferrara, E. (2005). Preferences for redistribution in the land of opportunities. Journal of Public Economics, 89(5-6), 897-931.

Benabou, R., \& Tirole, J. (2006). Belief in a just world and redistributive politics. The Quarterly Journal of Economics, 121(2), 699-746.

Callaway, B., \& Sant'Anna, P. H. (2021). Difference-in-differences with multiple time periods. Journal of Econometrics, 225(2), 200-230.

Collier, R. B. (1999). Paths toward democracy: The working class and elites in Western Europe and South America. Cambridge University Press.

Collier, R. B., \& Collier, D. (1991). Shaping the political arena. Princeton University Press.

Down, I., \& Wilson, C. J. (2013). A rising generation of Europeans? Life-cycle and cohort effects on support for 'Europe'. European Journal of Political Research, 52(4), 431-456.

Esping-Andersen, G. (1990). The three worlds of welfare capitalism. Princeton University Press.

Geddes, B. (1999). What do we know about democratization after twenty years?. Annual Review of Political Science, 2(1), 115-144.

Gerschenkron, A. (1962). Economic backwardness in historical perspective. The Political Economy Reader: Markets as Institutions, 211-228.

Giuliano, P., \& Spilimbergo, A. (2014). Growing up in a recession. Review of Economic Studies, 81(2), 787-817.

Goodman-Bacon, A. (2021). Difference-in-differences with variation in treatment timing. Journal of Econometrics, 225(2), 254-277.

Grasso, M. T., Farrall, S., Gray, E., Hay, C., \& Jennings, W. (2019). Thatcher's children, Blair's babies, political socialization and trickle-down value change: An age, period and cohort analysis. British Journal of Political Science, 49(1), 17-36.

Haggard, S., \& Kaufman, R. R. (2012). Inequality and regime change: Democratic transitions and the stability of democratic rule. American Political Science Review, 495-516.

Hagopian, F. (1990). "Democracy by undemocratic means"? Elites, political pacts, and regime transition in Brazil. Comparative Political Studies, 23(2), 147-170.

Hall, P. A. (2017). The political sources of social solidarity. In Banting and Kymlicka, eds., The strains of commitment: The political sources of solidarity in diverse societies. Oxford University Press, 201-232. 
Inglehart, R. (1971). The silent revolution in Europe: Intergenerational change in post-industrial societies. The American political science review, 991-1017.

Inglehart, R. (1990). Culture shift in advanced industrial society. Princeton University Press.

Inglehart, R. (2002). Gender, aging, and subjective well-being. International Journal of Comparative Sociology, 43(3-5), 391-408.

Inglehart, R. \& Norris, P. (2003). Rising tide: Gender equality and cultural change around the world. Cambridge University Press.

Inglehart, R., \& Norris, P. (2017). Trump and the populist authoritarian parties: the silent revolution in reverse. Perspectives on Politics, 15(2), 443-454.

Knutsen, C. H., \& Wegmann, S. (2016). Is democracy about redistribution?. Democratization, 23(1), 164-192.

Krosnick, J. A., \& Alwin, D. F. (1989). Aging and susceptibility to attitude change. Journal of Personality and Social Psychology, 57(3), 416.

Mainwaring, S., \& Bizzarro, F. (2019). The fates of third-wave democracies. Journal of Democracy, 30(1), 99-113.

Neundorf, A., \& Soroka, S. (2018). The origins of redistributive policy preferences: political socialisation with and without a welfare state. West European Politics, 41(2), 400-427.

Norris, P. (Ed.). (1999). Critical citizens: Global support for democratic government. Oxford.

Norris, P., \& Inglehart, R. (2019). Cultural backlash: Trump, Brexit, and authoritarian populism. Cambridge University Press.

O’Donnell, G. (1988). Bureaucratic authoritarianism. University of California Press.

Pharr, S. (1981). Political women in Japan. University of California Press.

Pierson, P. (1993). When effect becomes cause: Policy feedback and political change. World Politics, 45(4), 595-628.

Pierson, P. (1996). The new politics of the welfare state. World Politics, $\quad 48(2), 143-179$.

Sun, L., \& Abraham, S. (2021). Estimating dynamic treatment effects in event studies with heterogeneous treatment effects. Journal of Econometrics, 225(2), 175-199.

Treisman, D. (2020). Democracy by mistake: How the errors of autocrats trigger transitions to freer government. American Political Science Review, 114(3), 792-810. 


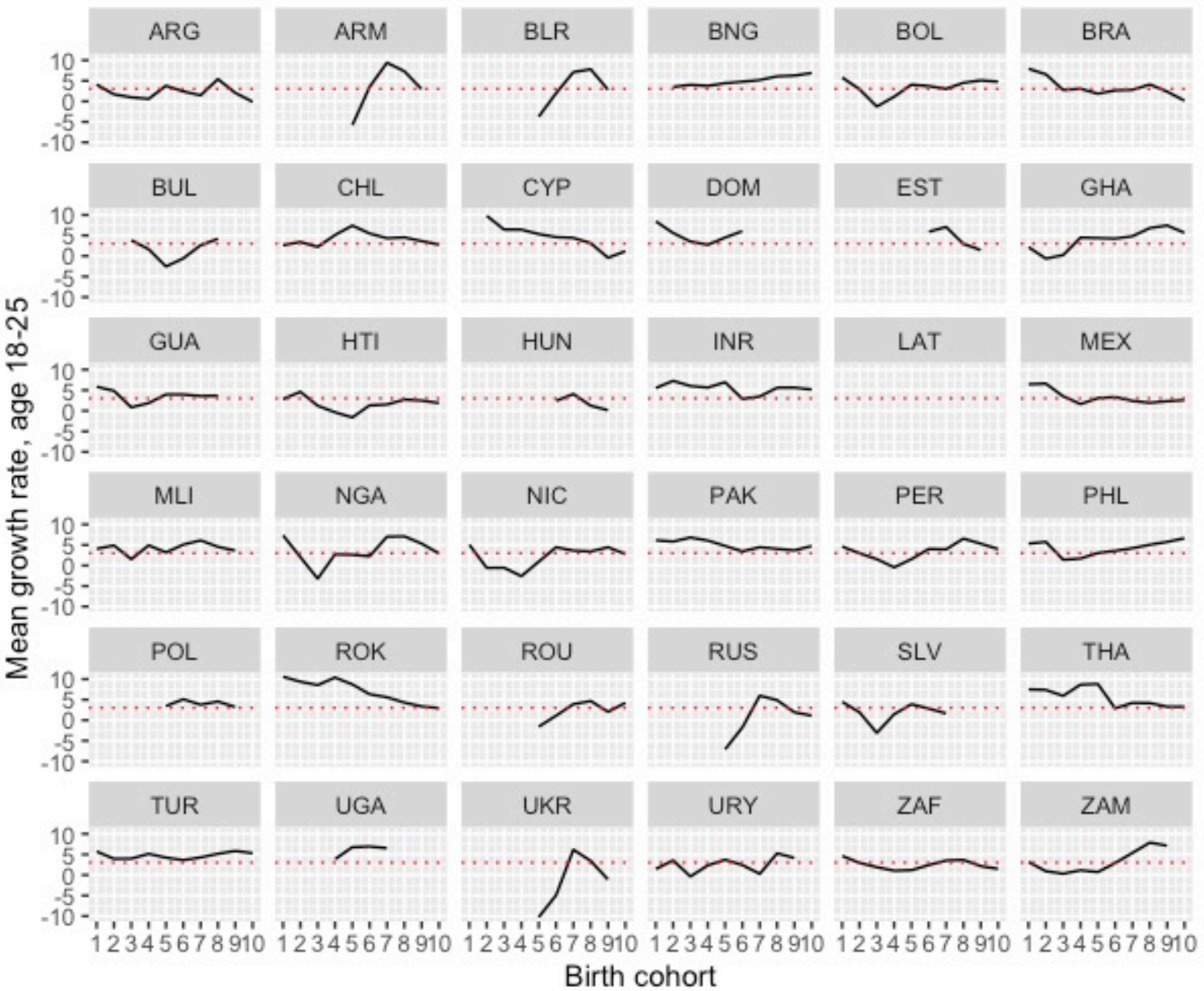

Figure 1: GDP growth by country and birth cohort (red line = recession) 


\begin{tabular}{|c|c|c|c|c|c|}
\hline \multirow{2}{*}{$\begin{array}{l}\text { Dependent Variable: } \\
\text { Model: }\end{array}$} & \multicolumn{5}{|c|}{ Agree: incomes should be more equal } \\
\hline & (1) & $(2)$ & $(3)$ & $(4)$ & $(5)$ \\
\hline \multicolumn{6}{|l|}{ Variables } \\
\hline Experienced a distributive transition & $\begin{array}{c}0.052 \\
(0.522)\end{array}$ & $\begin{array}{c}0.029 \\
(0.541)\end{array}$ & $\begin{array}{l}-0.530 \\
(0.460)\end{array}$ & $\begin{array}{l}-0.593 \\
(0.543)\end{array}$ & $\begin{array}{l}-0.845 \\
(0.607)\end{array}$ \\
\hline Age 18-25 (impressionable) during transition & $\begin{array}{c}0.023 \\
(0.115)\end{array}$ & $\begin{array}{c}0.046 \\
(0.139)\end{array}$ & $\begin{array}{l}-0.197 \\
(0.146)\end{array}$ & $\begin{array}{c}-0.295^{* *} \\
(0.127)\end{array}$ & $\begin{array}{c}-0.338^{* * *} \\
(0.118)\end{array}$ \\
\hline Impressionable during distributive transition & $\begin{array}{c}0.001 \\
(0.112)\end{array}$ & $\begin{array}{l}-0.012 \\
(0.144)\end{array}$ & $\begin{array}{l}0.254^{*} \\
(0.138)\end{array}$ & $\begin{array}{l}0.272^{* *} \\
(0.130)\end{array}$ & $\begin{array}{l}0.301^{* *} \\
(0.124)\end{array}$ \\
\hline $\begin{array}{l}\text { Grew up (experienced age 18-25) in a... } \\
\text { Rich country }\end{array}$ & $\begin{array}{l}-0.084 \\
(0.095)\end{array}$ & $\begin{array}{c}0.283^{* * *} \\
(0.096)\end{array}$ & & & \\
\hline Rich country $\times$ distributive transition & & $\begin{array}{c}-0.348^{* *} \\
(0.163)\end{array}$ & & & \\
\hline Rich country $\times$ impressionable & & $\begin{array}{c}-0.383^{* * *} \\
(0.122)\end{array}$ & & & \\
\hline Rich country $\times$ distributive $\times$ impressionable & & $\begin{array}{l}0.302^{*} \\
(0.154)\end{array}$ & & & \\
\hline Recession & & & $\begin{array}{c}-0.427^{* *} \\
(0.175)\end{array}$ & $\begin{array}{c}-0.437^{* *} \\
(0.167)\end{array}$ & $\begin{array}{c}-0.395^{* *} \\
(0.146)\end{array}$ \\
\hline Recession $\times$ distributive transition & & & $\begin{array}{l}0.487^{* *} \\
(0.187)\end{array}$ & $\begin{array}{c}0.534^{* * *} \\
(0.157)\end{array}$ & $\begin{array}{c}0.484^{* * *} \\
(0.135)\end{array}$ \\
\hline Recession $\times$ impressionable & & & $\begin{array}{c}0.034 \\
(0.260)\end{array}$ & $\begin{array}{l}0.025 \\
(0.263)\end{array}$ & $\begin{array}{l}-0.056 \\
(0.278)\end{array}$ \\
\hline Recession $\times$ distributive $\times$ impressionable & & & $\begin{array}{l}-0.105 \\
(0.261)\end{array}$ & $\begin{array}{l}-0.173 \\
(0.260)\end{array}$ & $\begin{array}{l}-0.102 \\
(0.265)\end{array}$ \\
\hline Unequal country & & & & $\begin{array}{l}-0.430^{*} \\
(0.237)\end{array}$ & $\begin{array}{l}-0.466^{*} \\
(0.269)\end{array}$ \\
\hline Unequal country $\times$ distributive transition & & & & $\begin{array}{l}0.127 \\
(0.294)\end{array}$ & $\begin{array}{c}0.268 \\
(0.303)\end{array}$ \\
\hline Unequal country $\times$ impressionable & & & & $\begin{array}{c}0.126 \\
(0.207)\end{array}$ & $\begin{array}{c}0.175 \\
(0.227)\end{array}$ \\
\hline Unequal country $\times$ distributive $\times$ impressionable & & & & $\begin{array}{c}0.116 \\
(0.220)\end{array}$ & $\begin{array}{c}0.084 \\
(0.232)\end{array}$ \\
\hline Welfare state & & & & & $\begin{array}{l}-0.590 \\
(0.674)\end{array}$ \\
\hline Welfare state $\times$ distributive transition & & & & & $\begin{array}{c}0.597 \\
(0.701)\end{array}$ \\
\hline Welfare state $\times$ impressionable & & & & & $\begin{array}{c}0.280 \\
(0.198)\end{array}$ \\
\hline Welfare state $\times$ distributive $\times$ impressionable & & & & & $\begin{array}{c}0.406 \\
(0.555)\end{array}$ \\
\hline Individual controls & Yes & Yes & Yes & Yes & Yes \\
\hline Country FE & Yes & Yes & Yes & Yes & Yes \\
\hline Survey year FE & Yes & Yes & Yes & Yes & Yes \\
\hline Birth cohort FE & Yes & Yes & Yes & Yes & Yes \\
\hline Period since transition $\mathrm{FE}$ & Yes & Yes & Yes & Yes & Yes \\
\hline Observations & 74,884 & 74,884 & 84,424 & 84,424 & 84,424 \\
\hline $\mathrm{R}^{2}$ & 0.10705 & 0.10715 & 0.10376 & 0.10398 & 0.10414 \\
\hline
\end{tabular}

Signif. Codes: ***: 0.01, **: 0.05, *: 0.1

Table 1: Transition experiences, economic socialization, ad support for redistribution 


\begin{tabular}{|c|c|c|c|c|c|c|}
\hline $\begin{array}{l}\text { Dependent Variables: } \\
\text { Model: }\end{array}$ & $\begin{array}{l}\text { hard work } \\
\quad(1)\end{array}$ & $\begin{array}{l}\text { competition } \\
(2)\end{array}$ & $\begin{array}{l}\text { dem. as } \\
\text { redist. } \\
\quad(3)\end{array}$ & $\begin{array}{l}\text { dem. as } \\
\text { unemp. aid } \\
(4)\end{array}$ & $\begin{array}{l}\text { post- } \\
\text { materialist } \\
\quad(5)\end{array}$ & $\begin{array}{l}\text { best } \\
\text { system } \\
(6)\end{array}$ \\
\hline \multicolumn{7}{|l|}{ Variables } \\
\hline Distributive transition & $\begin{array}{l}-0.285 \\
(0.255)\end{array}$ & $\begin{array}{c}0.063 \\
(0.190)\end{array}$ & $\begin{array}{l}-0.013 \\
(0.026)\end{array}$ & $\begin{array}{l}-0.011 \\
(0.030)\end{array}$ & $\begin{array}{c}0.170 \\
(0.131)\end{array}$ & $\begin{array}{c}0.029 \\
(0.026)\end{array}$ \\
\hline Impressionable during transition & $\begin{array}{c}0.076 \\
(0.188)\end{array}$ & $\begin{array}{c}0.056 \\
(0.160)\end{array}$ & $\begin{array}{c}0.004 \\
(0.017)\end{array}$ & $\begin{array}{c}0.022 \\
(0.022)\end{array}$ & $\begin{array}{c}0.171^{* * *} \\
(0.051)\end{array}$ & $\begin{array}{c}0.038^{* * *} \\
(0.011)\end{array}$ \\
\hline $\begin{array}{l}\text { Impressionable during distributive } \\
\text { transition }\end{array}$ & $\begin{array}{c}0.051 \\
(0.193)\end{array}$ & $\begin{array}{l}-0.059 \\
(0.173)\end{array}$ & $\begin{array}{l}-0.016 \\
(0.020)\end{array}$ & $\begin{array}{l}-0.029 \\
(0.024)\end{array}$ & $\begin{array}{c}-0.158^{* * *} \\
(0.057)\end{array}$ & $\begin{array}{c}-0.043^{* * *} \\
(0.013)\end{array}$ \\
\hline $\begin{array}{l}\text { Grew up (age 18-25) in a... } \\
\text { Recession }\end{array}$ & $\begin{array}{c}0.012 \\
(0.119)\end{array}$ & $\begin{array}{c}0.041 \\
(0.114)\end{array}$ & $\begin{array}{c}0.010 \\
(0.015)\end{array}$ & $\begin{array}{c}0.017^{* * *} \\
(0.006)\end{array}$ & $\begin{array}{c}0.110 \\
(0.073)\end{array}$ & $\begin{array}{c}-0.012^{*} \\
(0.006)\end{array}$ \\
\hline Recession $\times$ distributive transition & $\begin{array}{l}-0.006 \\
(0.129)\end{array}$ & $\begin{array}{l}-0.036 \\
(0.129)\end{array}$ & $\begin{array}{l}-0.021 \\
(0.018)\end{array}$ & $\begin{array}{c}0.005 \\
(0.018)\end{array}$ & $\begin{array}{l}-0.090 \\
(0.080)\end{array}$ & $\begin{array}{c}0.013 \\
(0.012)\end{array}$ \\
\hline Recession $\times$ impressionable & $\begin{array}{c}0.260 \\
(0.221)\end{array}$ & $\begin{array}{l}-0.076 \\
(0.141)\end{array}$ & $\begin{array}{c}0.014 \\
(0.020)\end{array}$ & $\begin{array}{c}0.001 \\
(0.011)\end{array}$ & $\begin{array}{l}-0.145 \\
(0.088)\end{array}$ & $\begin{array}{c}-0.051^{* * *} \\
(0.011)\end{array}$ \\
\hline $\begin{array}{l}\text { Recession } \times \text { distributive } \times \\
\text { impressionable }\end{array}$ & $\begin{array}{l}-0.322 \\
(0.229)\end{array}$ & $\begin{array}{l}-0.058 \\
(0.151)\end{array}$ & $\begin{array}{c}0.009 \\
(0.020)\end{array}$ & $\begin{array}{l}-0.007 \\
(0.024)\end{array}$ & $\begin{array}{c}0.110 \\
(0.096)\end{array}$ & $\begin{array}{c}0.059^{* * *} \\
(0.016)\end{array}$ \\
\hline Unequal country & $\begin{array}{c}0.133 \\
(0.198)\end{array}$ & $\begin{array}{l}-0.052 \\
(0.127)\end{array}$ & $\begin{array}{l}-0.005 \\
(0.012)\end{array}$ & $\begin{array}{l}-0.022 \\
(0.026)\end{array}$ & $\begin{array}{l}0.259^{* *} \\
(0.114)\end{array}$ & $\begin{array}{l}-0.006 \\
(0.012)\end{array}$ \\
\hline Unequal $\times$ distributive transition & $\begin{array}{c}0.060 \\
(0.299)\end{array}$ & $\begin{array}{l}-0.061 \\
(0.195)\end{array}$ & $\begin{array}{c}0.007 \\
(0.041)\end{array}$ & $\begin{array}{c}0.011 \\
(0.035)\end{array}$ & $\begin{array}{l}-0.178 \\
(0.146)\end{array}$ & $\begin{array}{l}-0.008 \\
(0.022)\end{array}$ \\
\hline Unequal $\times$ impressionable & $\begin{array}{l}-0.183 \\
(0.214)\end{array}$ & $\begin{array}{l}-0.062 \\
(0.230)\end{array}$ & $\begin{array}{l}-0.019 \\
(0.028)\end{array}$ & $\begin{array}{c}0.004 \\
(0.027)\end{array}$ & $\begin{array}{c}-0.216^{* * *} \\
(0.071)\end{array}$ & $\begin{array}{c}-0.040^{* * *} \\
(0.013)\end{array}$ \\
\hline $\begin{array}{l}\text { Unequal } \times \text { distributive } \times \\
\text { impressionable }\end{array}$ & $\begin{array}{c}0.186 \\
(0.238)\end{array}$ & $\begin{array}{c}0.298 \\
(0.266)\end{array}$ & $\begin{array}{c}0.017 \\
(0.030)\end{array}$ & $\begin{array}{l}-0.010 \\
(0.031)\end{array}$ & $\begin{array}{c}0.259^{* * *} \\
(0.080)\end{array}$ & $\begin{array}{c}0.046^{* * *} \\
(0.015)\end{array}$ \\
\hline Welfare state & $\begin{array}{l}0.739^{* *} \\
(0.349)\end{array}$ & $\begin{array}{l}-0.026 \\
(0.243)\end{array}$ & $\begin{array}{l}-0.012 \\
(0.045)\end{array}$ & $\begin{array}{c}0.040 \\
(0.041)\end{array}$ & $\begin{array}{c}0.205 \\
(0.156)\end{array}$ & $\begin{array}{l}-0.058^{*} \\
(0.033)\end{array}$ \\
\hline Welfare state $\times$ dist. transition & $\begin{array}{l}-0.571 \\
(0.403)\end{array}$ & $\begin{array}{c}0.343 \\
(0.254)\end{array}$ & $\begin{array}{l}-0.003 \\
(0.047)\end{array}$ & $\begin{array}{l}-0.019 \\
(0.043)\end{array}$ & $\begin{array}{l}-0.133 \\
(0.163)\end{array}$ & $\begin{array}{c}0.045 \\
(0.035)\end{array}$ \\
\hline Welfare state $\times$ impressionable & $\begin{array}{l}-0.191 \\
(0.223)\end{array}$ & $\begin{array}{l}0.338^{*} \\
(0.195)\end{array}$ & $\begin{array}{l}-0.021 \\
(0.027)\end{array}$ & $\begin{array}{l}-0.015 \\
(0.020)\end{array}$ & $\begin{array}{l}-0.035 \\
(0.100)\end{array}$ & $\begin{array}{c}0.017 \\
(0.019)\end{array}$ \\
\hline $\begin{array}{l}\text { Welfare state } \times \text { distributive } \times \\
\text { impressionable }\end{array}$ & $\begin{array}{l}0.909^{* *} \\
(0.425) \\
\end{array}$ & $\begin{array}{c}0.036 \\
(0.312) \\
\end{array}$ & $\begin{array}{c}0.026 \\
(0.051) \\
\end{array}$ & $\begin{array}{c}-0.019 \\
(0.032) \\
\end{array}$ & $\begin{array}{c}-0.128 \\
(0.245) \\
\end{array}$ & $\begin{array}{c}-0.061 \\
(0.049) \\
\end{array}$ \\
\hline Individual controls & Yes & Yes & Yes & Yes & Yes & Yes \\
\hline Country FE & Yes & Yes & Yes & Yes & Yes & Yes \\
\hline Year FE & Yes & Yes & Yes & Yes & Yes & Yes \\
\hline Birth cohort FE & Yes & Yes & Yes & Yes & Yes & Yes \\
\hline Period since transition FE & Yes & Yes & Yes & Yes & Yes & Yes \\
\hline Observations & 70,037 & 79,624 & 54,157 & 54,392 & 82,905 & 79,944 \\
\hline $\mathrm{R}^{2}$ & 0.08847 & 0.06177 & 0.10762 & 0.09236 & 0.07473 & 0.04297 \\
\hline
\end{tabular}

Signif. Codes: ***: 0.01, **: 0.05, *: 0.1

Table 2: Mechanism tests, section 6 